\title{
Integrated Team Design Projects at Carleton University
}

\author{
Paul V. Straznicky \\ R.G. Langlois \\ pstrazni@mae.carleton.ca \\ M. McDill \\ rlangloi@mae.carleton.ca \\ R. Miller \\ mmcdill@mae.carleton.ca \\ S.A. Sjolander \\ rmiller@mae.carleton.ca \\ D.A. Staley \\ ssjoland@mae.carleton.ca \\ StaleyDoug@cs.com \\ Department of Mechanical and Aerospace Engineering (M\&AE) \\ Carleton University, Ottawa K1S 5B6
}

\begin{abstract}
The engineering design curriculum is receiving muchdeserved attention at all universities in Canada and abroad, and many interesting approaches to design education are under development. One such approach is the topic of this paper. Its key feature is a $4^{\text {th }}$-year integrated team design project at M\&AE, a culmination of systematic design education that starts in the first year. The paper will describe this approach, the accomplishments and the plans for the future.
\end{abstract}

\section{Introduction}

Over the last decade, engineering design and the methods for its teaching have assumed an increasingly important role in Canadian universities as a result of pressures from industry and from the Canadian Engineering Accreditation Board (CEAB). With this focus, a number of methodologies to teach engineering design are under development at different universities. One approach that is original among Canadian universities has been evolving in the Department of Mechanical and Aerospace Engineering at Carleton University for the last fourteen years - a systematic design education process culminating in an integrated team design project.

The process starts in the first year course "Introduction to Engineering" where all engineering students learn about the design process, graphical design communication, design analysis, and management of experimental data, as well as engineering ethics, health and safety, environment and sustainability. In the second year, the "Engineering
Graphics and Design” course for M\&AE students, aims to deepen the knowledge of the design process, descriptive geometry, CAD skills, and fundamentals of engineering drawing. An integral part is a hands-on project where each student solves a design problem. The work contents include preparation of a proposal, fabrication of a simple proof-of-concept model and a rapid-prototyping manufactured model. The work is then summarized in a final report.

The third year offers specialized design courses. As an example, in the "Aerospace Design and Practice" course the students learn about the practices of the aerospace industry, conceptual sizing of aircraft, trade-off studies, loads on flight vehicles, structural concepts and structural integrity. Teams of three or four students apply the course material to develop aircraft concepts from a set of design requirements and produce final reports in the format of a journal paper. There is a similar course, "Mechanical Design and Practice", in the Mechanical Engineering program. Also, in the third year "Engineering Laboratory" course, student teams carry out and report on various experiments. They also have a competition to design, build, and test electromechanical systems to perform a specified function; for example, a device to generate the highest force with a standard electric motor and battery.

In the fourth year there are systems design courses. "Aerospace Systems Design” covers systems design approaches, certification of complex systems and design for safety. Different systems such as hydraulic, electrical, and avionics, are discussed with examples such as landing gear, environmental control, and spacecraft systems. Teams of up to five students design, analyze, and build working models of a 
different aerospace system every year. Each team also researches a selected aerospace accident and presents their case study, including the "systems lessons learned", to their colleagues. The course "Mechanical Systems Design” is, again, similar.

\section{Final year team project}

The fourth-year project is a culmination of the design education process. It has evolved significantly since the early nineties when a team project in aircraft design was devised for the new "B.Eng. Aerospace" program at Carleton - the first Aerospace class graduated in 1992. Design of aircraft was initially the sole topic, and design of spacecraft was added in 1993-1994. These were "paper projects", with oneyear duration and a new topic every year. Prototype fabrication and testing were added as the approach evolved, and necessitated a change to multi-year projects.

M\&AE made this approach standard for both the Mechanical and Aerospace Engineering programs starting in the year 1999-2000. Today there are six multi-disciplinary projects, namely, designs of

- Geophysical survey unmanned air vehicle system

- Zero-emission gas turbine engine

- Versatile multipurpose vehicle simulator

- Formula SAE racing car

- Fuel cell powered robotic mining vehicle

- $\quad$ Rapid deployment spacecraft system.

The original project objectives as stated in the program calendar are to give the students "Opportunities to exercise initiative, engineering judgment, self-reliance and creativity, in a team environment similar to industry." Inherent in these are other general objectives such as applying engineering knowledge to the design of complex products and systems, presenting the work through reports and design reviews and, implementing the designs through experiments, demonstrator prototypes and in some instances fully-functional prototypes.

Specific project objectives are realistic and are clearly defined by "customers" (industry or government) or with significant customer inputs. They are used to develop the tasks for the groups and the individual team members through iterative planning. Each team numbers up to thirty students divided into groups based on the work contents. Each group is supervised by one or two Lead Engineers, either faculty members or experienced engineers from outside the university. A Project Manager is responsible for co-ordination of the work and fulfillment of the project objectives. Each M\&AE faculty member serves on one project, either as a Lead Engineer or a Project Manager (typically, a faculty member with industrial experience). This approach is heavily resource-intensive; however, it has proven to be highly rewarding for students and faculty.

One of the important contributions of the projects to the training of young engineers is the simulation of an environment in a small engineering company. This has direct relevance to Small and Medium Enterprises (SMEs) and to the departments within larger companies. Team dynamics similar to those in a company develop gradually through continuous encouragement by Lead Engineers and by interaction with team colleagues. Further reinforcement is provided by activities such as weekly team meetings, informal and formal design reviews, and the recording of all engineering work in design reports or design memoranda. Lead Engineers look for and encourage students with leadership potential to assume larger roles within the project team.

The project methodology is continuously under review and improvements are made every year. Some new developments that are currently being addressed include:

- More effort to ensure similar design experiences for every design team for each academic year regardless of the design stage of the project. A conceptual design phase normally involves little hardware manufacturing and testing compared to the same project a few years later.

- Integration of graduate students within the teams. These Master's students are being assigned thesis topics aimed at improving the team design solutions or at solving difficult analysis problems. Presence of the graduate students also provides the needed team continuity from year to year.

- Greater involvement of undergraduate students from lower years to further improve year-to-year continuity.

\section{Project management}

All design teams use the same basic project management approach whose key features include:

- A Design Integration group responsible for configuration control, design database, integration of solid models, resolving problems, and administration tasks such as minutes of meetings, records of all design reports, and co-ordination of formal design reviews, to name a few.

- Web-based communications via project web pages resulting in an essentially "paperless office”.

- Two formal design reviews, one (in the fall) internal and one (mid-March) external. Up to twenty experts from industry and government attend each external review, and judge the 
students' performance. This day is an excellent opportunity for the students to network.

- Final reporting through CD-ROMs to pass the developed design knowledge effectively to the succeeding project team. A subset CD is distributed to interested external parties.

The day-to-day running of the projects varies depending on the team, the topic, and the project phase. Regular meetings of Project Managers with the M\&AE Chair assure a certain degree of consistency, such as in organizing project reviews and student grading.

\section{Facilities and tools}

M\&AE facilities to carry out the project work include three dedicated well-equipped design rooms (with computers, meeting and library spaces), workshop facilities, rapid prototyping equipment, and prototype assembly rooms. When machining or other fabrication is needed, students do the work under the supervision of shop technicians. Design tools that the teams use are numerous and provide a high level of sophistication. They range from technical tools such as CFD, FEM, and multi-body dynamics packages to management tools including manufacturing planning and project planning and scheduling.

\section{Collaboration}

Industry and government organizations have welcomed the team project initiative and provide us with constructive feedback and encouragement. They also support the projects financially and in-kind, and the level of support is increasing from year to year. The participation of industry experts in the project reviews has already been mentioned. However, we also are fortunate to have external engineers who volunteer their time to serve as Lead Engineers; during the 2003-2004 academic year there were eight of them. Also, every year several outside engineers present seminars on project management or technical topics of significance to the projects. The level of offcampus collaboration varies from project to project, and will be described below.

Within Carleton University, collaboration is also evolving. Participation by students from other departments is being actively pursued and is increasing steadily. In the mid 90's, students from the School of Industrial Design (SID) started working with the aircraft design project on cockpit and cabin designs including full-scale mock-ups. Now they are also involved in the Formula SAE racing car. In the past two years, design groups from Systems and Computer Engineering (SCE) have been integrated in the Multipurpose Simulator Project, supervised by a SCE faculty member serving as a Lead Engineer and there have been Electronics Engineering students integrated into the Underground Mining Vehicle Project. A number of other collaboration possibilities are being pursued with two examples given below:

- Eric Sprott School of Business faculty and students would contribute in the areas of marketing, cost control and project management.

- Participation by the Department of Psychology (cognitive science) would enable us to consider human factors in more than one project.

\section{Project overviews}

The following pages provide overviews of the six projects covering the objectives, the multi-year plan and status, accomplishments and plans for the future.

\subsection{Carleton University simulator project \\ Project Manager: R.G. Langlois}

\section{Overview}

The Carleton University Simulator Project (CUSP), introduced in the 2002-2003 academic year, is the newest team design project. The decision to introduce this project was based on the growing prevalence of simulation in design, training, acquisition, human factors analysis, and incident investigation. Further, the design of a multifunctional vehicle simulator is compatible with teaching and research interests of members of the Faculty of Engineering and Design at Carleton - both within M\&AE and beyond. The concept received strong support from the Canadian simulation community as it is projected that demand for recent graduates with the skill-set required to integrate seamlessly into this industry will significantly exceed supply over the next decade. Due to this strong external support, significant opportunity exists for students to interact with counterparts in industry and government during their involvement with CUSP. This interaction directly supports the objective of imparting critical soft skills to students.

The long-term objectives of CUSP are to develop a complete and flexible simulation facility at Carleton including a variety of mathematical models, a versatile motion platform, flexible visual and auditory cues, and a reconfigurable user interface, all interoperating compliant with the new industry-standard high-level computer architecture (HLA). The facility will be used to support research and education objectives from industry, university, and government. It will also play a central role in simulation education at Carleton. 
This academic year, the CUSP design team comprised 5 faculty members and 30 students studying Aerospace Engineering, Mechanical Engineering, Systems and Computer Engineering, and Business at Carleton. Students from Cognitive Science and Architecture will likely be involved in Year 3 of the project. The project manager, Prof. Rob Langlois, brings industrial experience in the management of dynamic systems, modelling, and simulation R\&D projects. The five lead engineers, who have varied backgrounds and interests related to the project, and students are organized into teams by area of expertise. The five teams are: Actuation (ACT), Integration (INT), Kinematics and Dynamics (DYN), Structures (STR), and Systems (SYS) led by Prof. John Gaydos, Ms. Amanda Feldman, Prof. John Hayes, Prof. ChoonLai Tan, and Prof. Trevor Pearce, respectively. In a matrix structure similar to industry, students are also assigned to one or more functional task-oriented groups as indicated in Table 1. Additional expertise comes from graduate students and faculty in the Departments of Cognitive Science, Architecture, and Electronics as well as from numerous supportive individuals in industry and government.

\section{Current status}

The short-term objectives completed in Years 1 and 2 of the project were to survey existing applications, requirements, shortcomings, and configurations for simulator motion platforms appropriate for a range of vehicle types; develop a preliminary design for a six-degree-of-freedom motion base (NASP); and simultaneously design and build an HLA-compliant full-scale Several Integrated Degreeof-Freedom Demonstrator (SIDFreD) initially based on a road vehicle. The demonstrator contains mathematical models, user input, three degrees of actuation, and graphical display. While a simple system, the demonstrator established an approach that is being followed for the development of the fullmotion simulator concept, illustrated in Figure 1 along with SIDFreD.

Table 1. CUSP matrix organizational structure

\begin{tabular}{llllll}
\hline grouplteam & INT & ACT & DYN & STR & SYS \\
\hline Business & ST 1 & ST 2 & $\ldots$ & & \\
SIDFreD & ST 3 & $\ldots$ & & & \\
NASP & $\ldots$ & & & & \\
Safety & & & & & \\
Human Factors & & & & & \\
Vehicle Simulation & & & & \\
\hline
\end{tabular}

Objectives for Year 3 of the project (2004-2005) include comprehensive performance testing and refining the structural, mathematical modelling, and software aspects of the technology demonstrator, advancing the design of the six-degree-of-freedom platform and associated facility, and focusing considerable attention on visual and auditory cues.

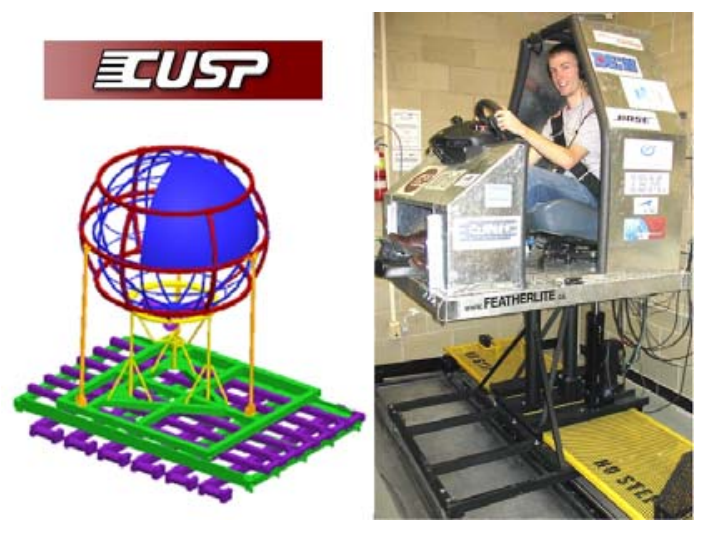

Figure 1. CUSP logo (upper left), full-motion simulator concept (lower left), and SIDFreD technology demonstrator (right)

\section{Distinctive features}

The CUSP project necessarily requires skills from a broad range of fields spanning cognitive science through computer engineering. As an example, development of a motion platform washout control algorithm requires thorough understanding of human proprioceptors for determination of motion detection thresholds, dynamics and control for algorithm development, and computer engineering for distributed real-time implementation minimizing latency. This has led to significant interdisciplinary applied research, publication of several technical papers, and a patent application. CUSP has also contributed significantly to the success of a $\$ 28.4$ million interdisciplinary proposal to establish the Carleton University Centre for Advanced Studies in Visualization and Simulation (V-SIM) that will further facilitate interdisciplinary research of the type involved with CUSP.

\subsection{A fuel cell powered autonomous underground mining vehicle \\ Project Manager: M. McDill}

\section{Overview}

2003-2004 marked the fourth year of a five-year project to design an Autonomous Underground Mining Vehicle (AUMV). The principal purpose of the AUMV is to increase safety in hard rock mining by reducing the role of humans in dangerous deep mine environments. A related increase in productivity is anticipated. The AUMV, a load-haul-dump vehicle, moves ore from the mine drift to the ore pass. The fuel 
cell power plant will reduce ventilation costs ${ }^{1}$, particularly in the upper portions of the mine.

Dr. John Udd, Principal Scientist at National Resources Canada (NRCan) is a technical advisor to the project. NRCan has supported the project through a lend-lease equipment agreement. INCO Ltd. and Les Resources Aur have hosted tours of mines. DYI Technologies (Ottawa), Sensor Technology (Toronto) the Fuel Cell Store (Boulder) and Materials and Manufacturing Ontario (Connections) support the project. The AUMV participates in the Fuel Cell Propulsion Institute Consortium (Vehicles Project, Colorado).

\section{Current status}

The team of 28 included mechanical and aerospace engineering students as well as one or two from electrical engineering formed into groups including: Integration; Structures; Guidance, Navigation and Control; Drive Train; Fuel Cell; and Visualization. Two principal focuses have evolved: the design of the full-scale virtual vehicle (including a virtual mine) and the parallel development of a $1 / 4-$ scale proof-of-concept (POC) vehicle. Students make use of industry-standard software; e.g., Pro/Engineer, Pro/Mechanica and 3D Studio MAX.

The AUMV, Figure 2, is approximately $9 \mathrm{~m}$ long and $2.8 \mathrm{~m}$ wide with a payload capacity of $10,000 \mathrm{~kg}$. It uses a $200 \mathrm{~kW}$ proton exchange membrane fuel cell - ultracapacitor system. The drive train uses four independent wheel motors. The AUMV incorporates sensors for in-drift travelling.

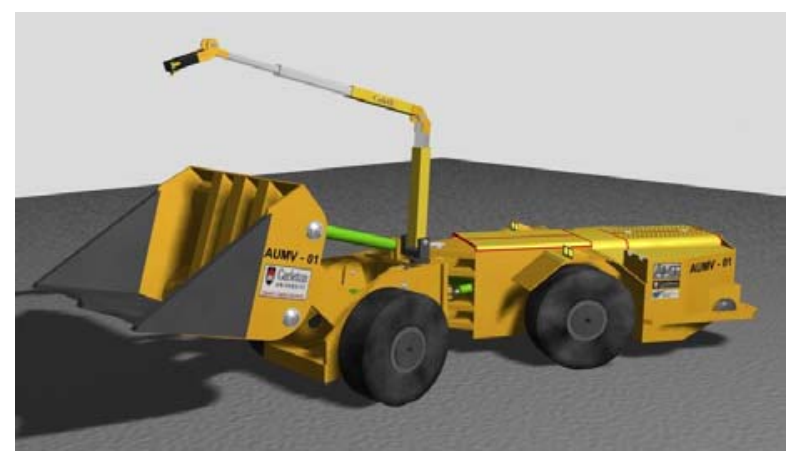

Figure 2. AUMV (Visualization group)

\footnotetext{
${ }^{1}$ In 2004, the project was one of 19 selected nationally by the NRCan Energy Ambassador Program. A business plan for the AUMV reached the semi-finals in the Eastern Ontario Technology Venture Challenge.
}

A vision-grappler arm allows surface-based trouble shooting via wireless communication. Year 5 will deal with dynamic modelling, structural design and the vision-grappler arm.

The POC, Figure 3, functions as a test bed. It has four wheel motors, sensors and is powered by a fuel cell - ultracapacitor system. In Year 5, a hydride bed will be added, as will a new controller, wheel encoder/motors and a $1 / 4$-scale vision-grappler arm.

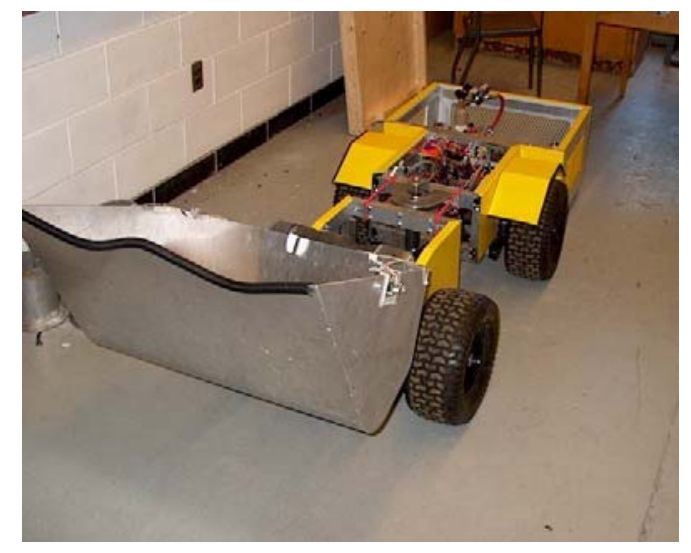

Figure 3. POC test bed (POC group)

Distinctive features

The mine tours require significant industry involvement but demonstrate the challenging design environment. Feedback from industry has been essential to the design of the AUMV.

Building a full-scale prototype is beyond the scope of the team. However, the design of a virtual vehicle and virtual mine is an excellent substitute. When combined with the POC, it presents the students with a complementary design-build experience.

\subsection{Formula SAE (FSAE) race car \\ Project Manager: R.E. Miller}

\section{Overview}

The FSAE race car is one of the annual competitions in the SAE International "collegiate design series". Each year in May, approximately 140 schools from around the world race cars designed and built within guidelines set out by the SAE. The FSAE race car is a fully suspended, open-wheel, opencockpit car with a 600cc motorcycle engine. Safety and performance requirements necessitate a thorough understanding of the structural aspects, vehicle dynamics, IC engines and manufacturing processes. The competition includes a focus on engineering design, marketing and cost, as well as several static and dynamic events with the cars themselves. 
A picture of the 2004 car, which will be Carleton's seventh consecutive entry to the competition, is shown in Figure 4.

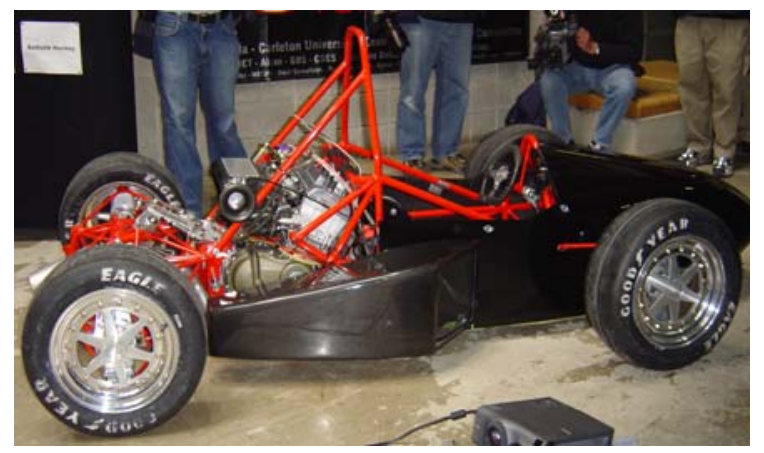

Figure 4. The 2004 Carleton FSAE car

This year's team of 18 students was divided into 5 sub-groups: Structures, Dynamics, Engine, Testing/Aerodynamics and Integration. The project was overseen by 4 lead engineers, 3 of whom are faculty members while the $4^{\text {th }}$ is a professional engineer with considerable racing experience.

\section{Current status}

The FSAE project is unique from the others in that it is "on-going", where the final goal (a functional car at the competition) is the same each year. However, the design philosophy each year is to build on the strengths of previous entries, and as such each year there is a goal of advancing the level of performance of the car. This year, the focus was on three main areas: weight reduction, component reliability and simplification of manufacturing and assembly.

The first half of the year (from September to December) focused on "paper design" and computer modelling, including finite element analysis, fullvehicle multi-degree of freedom dynamics simulations and engine flow and combustion simulations. Figure 5 shows an example of the computer-aided design process. On the left of the figure is a Pro/E CAD drawing of the front upright. The results of an FEM analysis to determine the stresses on the upright in service are shown on the right.

From Christmas until May, the focus was on manufacturing, assembly, and testing of the design. During this stage, the students work extensively with the department's own machine shop, as well as with several local machine shops and fabricators to manufacture the car. The project is completed through a combination of the students' own manufacturing efforts and professionally manufactured components in order to balance the educational experience with the tight time frame required to make it to competition. Much of the professional manufacturing is provided as in-kind sponsorship or at discounted rates.

\section{Distinctive features}

The external deliverables related to the competition make this project a demanding one. Time is very short for the students to design, build and test the car, which must be substantially different from previous entries to qualify for the competition. As well, the cost to produce the car is typically in excess of $\$ 50,000$ when in-kind manufacturing costs are included. On the other hand, students enjoy the competition enormously, and the 4-day event itself is a tremendous learning experience because the students meet and interact with many engineers from the racing and automotive industries. Many students have made contacts at the competition that have lead directly to automotive engineering jobs.

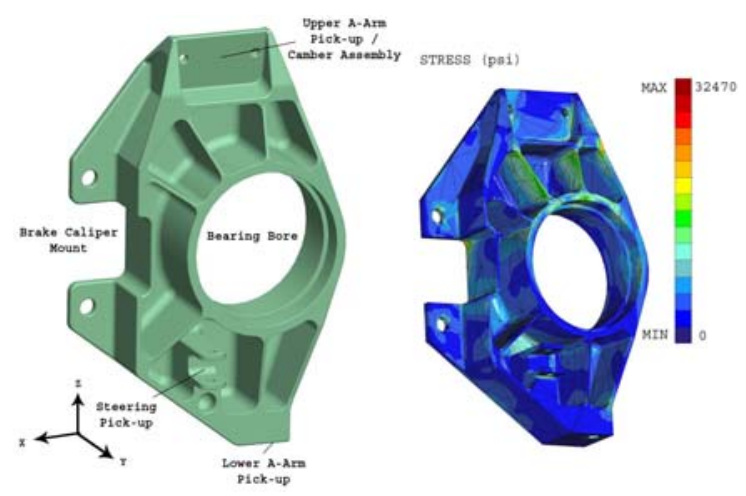

Figure 5. CAD \& FEM models of the uprights

\subsection{Zero-Emission gas-turbine engine \\ Project Manager: S.A. Sjolander}

\section{Overview}

The Department of Mechanical and Aerospace Engineering has a long history of teaching and research in the areas of turbomachinery and gas turbine engines. Therefore, when the team design projects were extended to the full graduating class, it was natural to include a project on the design of a gas turbine engine.

During the first two years, the focus was on a fairly conventional, open-cycle micro gas turbine engine for power generation. In the second year of the project, an Advanced Design group was formed to explore a much more novel concept: a zero-emission gas turbine engine based on a semi-closed cycle and with $\mathrm{CO}_{2}$ as the primary working fluid. The application was again distributed power generation, 
but with zero emission of greenhouse gases and other pollutants. The conceptual design for this plant became the starting point for the full design project in the following year. Furthermore, the technology was seen by Natural Resources Canada (NRCan) as one worth exploring. Consequently, a four-year contract was negotiated with NRCan to develop the engine concept and in this way to fund the project.

The plant currently being designed will have an output of $50 \mathrm{~kW}$. The engine will burn natural gas. This is supplied to the combustor with just sufficient oxygen for stoichiometric combustion. The main $\mathrm{CO}_{2}$ stream acts as the diluent gas. The only products of combustion are water and additional $\mathrm{CO}_{2}$. The water will be removed in a condenser and the extra $\mathrm{CO}_{2}$ will be bled off and sequestered. The plant will also include a recuperator for better thermal efficiency. The sequestered $\mathrm{CO}_{2}$ may have industrial uses, such as for enhanced oil and gas recovery in older fields; in any event, it will not be emitted to the atmosphere.

\section{Current status}

The second year of the planned four-year project has been completed. During 2003-2004 the team consisted of 28 students. They were subdivided into seven groups, according to responsibilities, such as Design Integration, Aerodynamics, Structures, etc. The groups were supervised by seven Lead Engineers, who included one graduate Teaching Assistant (a former team member) and David P. Kenny, retired Director of Engineering, Pratt \& Whitney Canada.

Preliminary design has been completed for all components and some have proceeded to detailed design. Figure 6 shows the assembly of the complete plant. The nominal goal is to have a prototype of this plant operational at the end of the project.

One of the benefits of having substantial outside funding is that it is possible to build and test actual hardware. Figure 7 shows the compressor design, a single-stage centrifugal machine with a pressure ratio of 7.0. This component has undergone complete aerodynamic and structural analysis, and a contract for the manufacture of five rotors was let in early 2004. Unfortunately, the manufacturer subsequently reported that the component was too complex and the tolerances too tight for the intended injection molding process. This was naturally a disappointment to the team, but provided an important lesson in manufacturability and design for manufacture. The rotor is currently being redesigned.

\section{Distinctive features}

The gas turbine project illustrates the synergy that can develop between an undergraduate design project and graduate-level research. The NRCan involvement with the project in fact began with a Master's thesis project on a related topic. It was subsequently realized that performing the preliminary design for the complete zero-emission plant was an effective way of identifying gaps in our knowledge and thereby identifying further research needs. The project has now come full circle. In May 2004 two Master's research projects will begin that address technical issues that have been identified by the undergraduate project. Both of the graduate students involved are past members of the gas turbine project team and their interest in graduate studies was stimulated by their involvement with the design project.

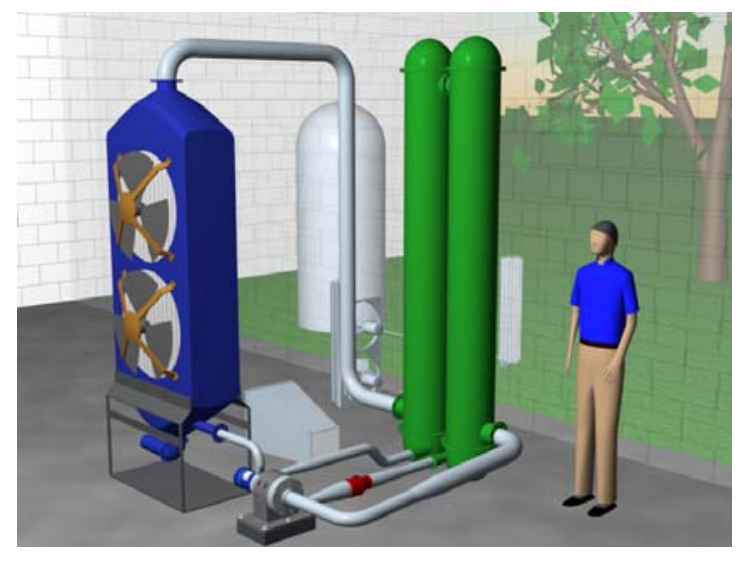

Figure 6. Zero-emission gas turbine

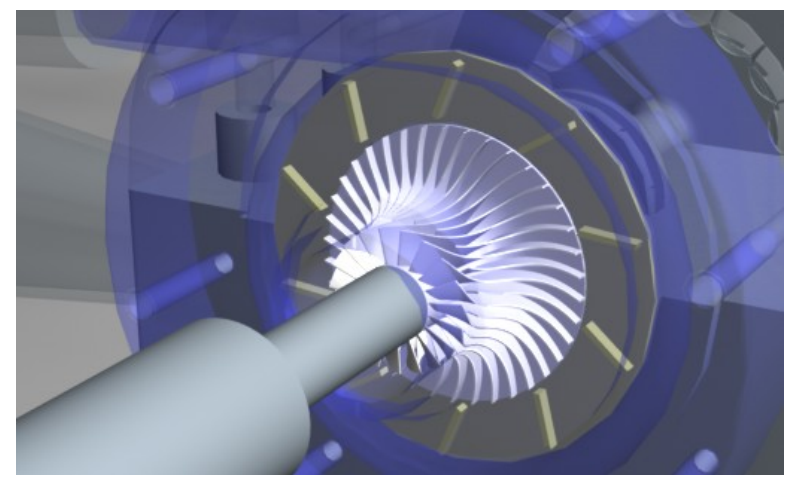

Figure 7. Centrifugal compressor 


\subsection{Spacecraft design project}

Project Manager: D.A. Staley

\section{Overview}

The spacecraft design project, in the second year of a multi-year project, addresses a Canadian need for rapid deployment of surveillance satellites. The applications include disaster management, forest fire detection, fisheries surveillance and other remote sensing missions such as agriculture optimization and minerals exploration. Due to a growing international uncertainty, access to foreign launch vehicles is no longer assured. This, coupled with the increasing capabilities of miniaturized components, has sparked a review of launch vehicle capabilities within Canada.

The current project addresses all three aspects of a Canadian based capability for space-based surveillance with an air-launched micro-satellite system consisting of:

- A launch vehicle for micro-satellites,

- A micro-satellite compatible with the launch vehicle,

- An infrared optical payload for the microsatellite.

Financial support this year has been provided by CRESTech and DND. Industrial participants include: Cesaroni Technologies, Gormley, Ontario; MDA, Richmond, B.C. and Routes, Ottawa, Ontario.

\section{Current status}

This year there were 22 students divided into three groups, the launch vehicle group with 9 students, the satellite group with 9 students, the payload group with 2 students and 2 students engaged in project management. One student acted as the systems manager in each of the launch vehicle and satellite groups. Thus, four of the students acted in a management role.

The launch vehicle group undertook a major trade study in September and October. After studying possible aircraft platforms, the C-130 Hercules was determined to be optimum with a launch vehicle deployed out of the rear cargo doors using parachutes, at an altitude of $10 \mathrm{~km}$, as depicted in Figure 8.

The launch vehicle design evolved into a threestage, all solid propellant rocket with a total mass of $7,300 \mathrm{~kg}$ and an overall length of $9.8 \mathrm{~m}$ as shown in Figure 9. It will be contained in a launch frame to which a five parachute cluster is attached. The threestage rocket can insert a $56 \mathrm{~kg}$ satellite into an $800 \mathrm{~km}$ sun synchronous orbit. Trajectory optimization was obtained using ASTOS, a software system developed at the University of Stuttgart for ESA/ESTEC. Carleton is the only Canadian university using ASTOS.
The satellite has a mass of $50 \mathrm{~kg}$ and includes deployable solar arrays. It can easily perform a roll manoeuvre of up to 30 degrees in either direction around the spacecraft roll axis so that the optical payload can point to targets of interest. Two small momentum wheels in a V-configuration, within the spacecraft pitch-yaw plane, permit a deadbeat manoeuvre to rapidly point the optical axis. A satellite sketch, with the solar arrays deployed, is shown in Figure 10.

The payload is a push broom imager based on microbolometer arrays operating in the 8 to $14 \mu \mathrm{m}$ wave band. Three separate wave bands are focused on three separate micro-bolometer linear arrays. The optical aperture is $30 \mathrm{~cm}$ allowing sufficient signal to noise ratio for an 8-bit dynamic range.

This project will continue next year with in-depth design of all three components of the air-launched micro-satellite.

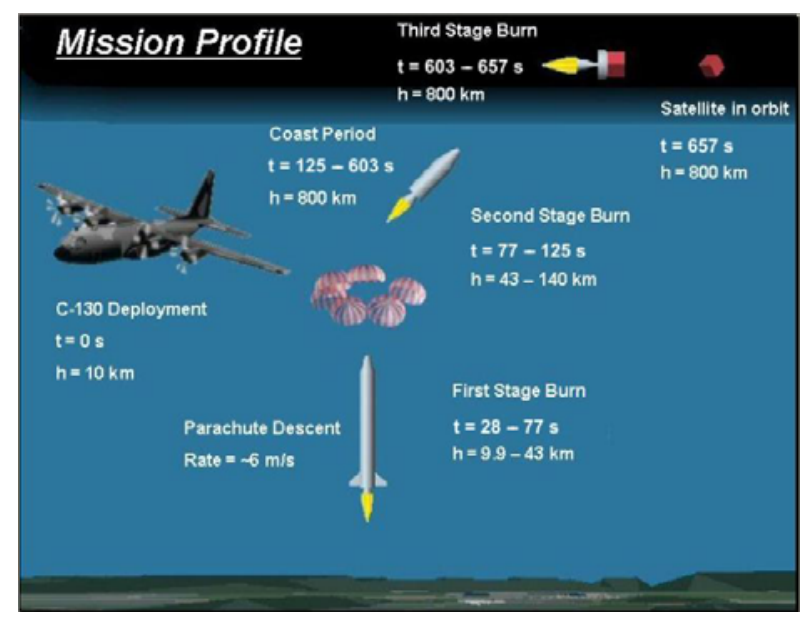

Figure 8. Mission profile

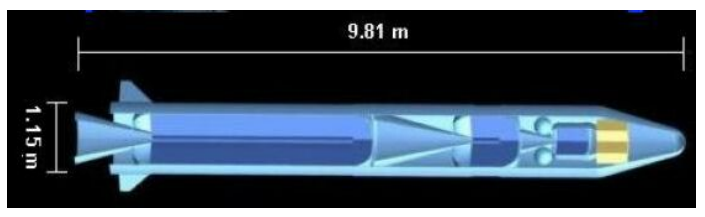

Figure 9. Launch vehicle 


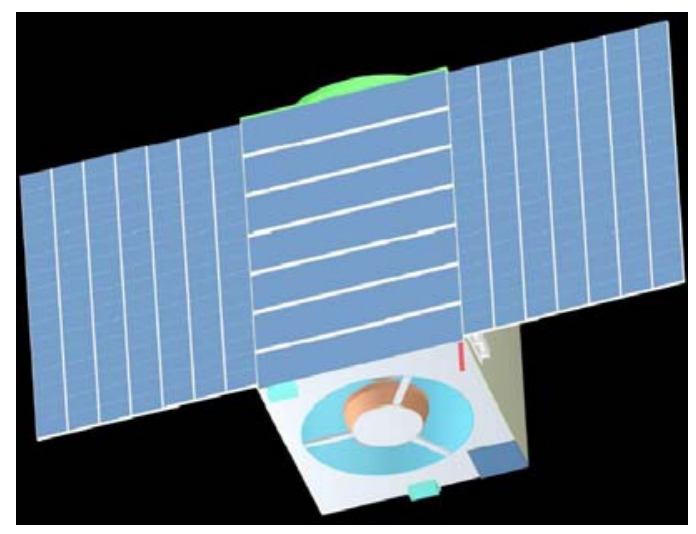

Figure 10. Satellite model

\subsection{GeoSurv unmanned aerial vehicle \\ Project Manager P.V. Straznicky}

\section{Overview}

GeoSurv is being developed in response to the requirements provided by Sander Geophysics Ltd. of Ottawa to design a low-flying, slow-speed Unmanned Aerial Vehicle (UAV) system with a 14-hour endurance, to be used for airborne geophysical surveys. The aircraft carries a $340 \mathrm{~kg}(750 \mathrm{lb})$ mission avionics package that includes magnetometers, gravimeters and sodium iodide crystals for detection of gamma rays. One of the challenging design issues is the need for the aircraft to follow the ground contours at an altitude down to $30 \mathrm{~m}$.

Additionally, certification requirements of UAVs for flight operations in controlled airspace must be adhered to. In Canada, Transport Canada requires socalled Special Flight Operation Certificates (SFOC) to ensure the necessary levels of safety.

\section{Current status}

Academic year 2003-04 was the second year of this project. The team included 30 students and 8 Lead Engineers three of whom were from outside the university, namely Dr. G. Marsters from AeroVations Inc., Mr. J. Bauer, an avionics engineer and Dr. J. Laliberté from the Institute for Aerospace Research. Also, two graduate students participated in the project. The team carried out three sub-projects dealing with the full-scale GeoSurv, its sub-scale demonstrator (SSD), and an avionics test bed (ATB).

Preliminary design of full-scale GeoSurv was completed with the exception of the avionics system. The aircraft, shown in Figure 11, has a $14.6 \mathrm{~m}$ wing span, $1,540 \mathrm{~kg}$ takeoff mass, and is powered by a 230 hp diesel engine.

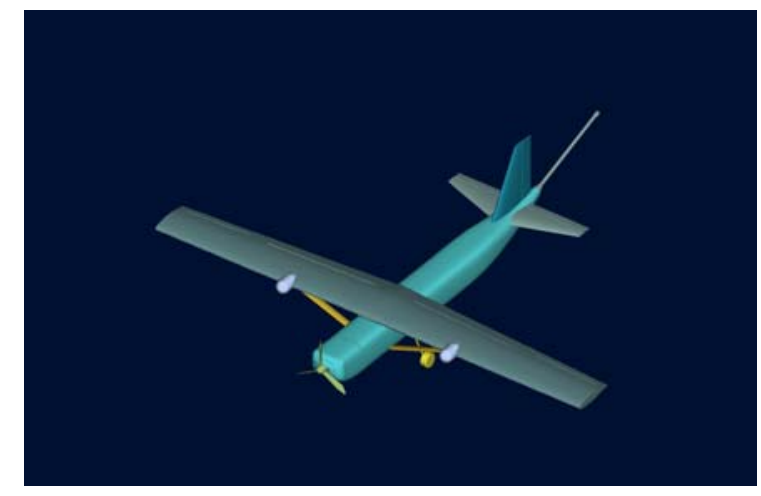

Figure 11. GeoSurv configuration

The SSD, a 1/12 scale of GeoSurv, was designed, built and tested in one of the M\&AE wind tunnels to determine its flying qualities. Figure 12 shows the SSD flying tethered in the wind tunnel.

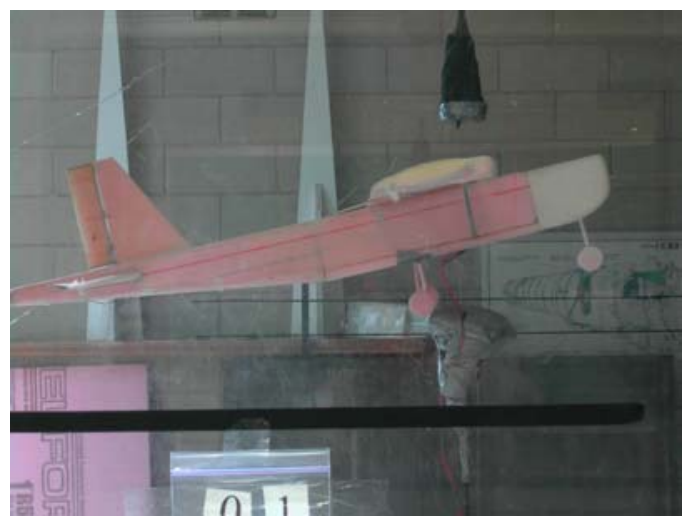

Figure 12. SSD in wind tunnel

The purpose of the ATB, seen in Figure 13, is to expose the students to the complexities of integrating avionics into an aircraft and to demonstrate autonomous flight. The aircraft is a 3-m wing span radio-controlled trainer built from a kit. It contains an autopilot with GPS navigation and a telemetry system. Following an extensive R/C flight test program, initial flights under autopilot control were accomplished.

For the academic year 2004-2005, our customer has defined a new set of the requirements for a smaller UAV. This aircraft will fly ultra-low level magnetic gradiometer surveys over a typical area of $10 \mathrm{~km}$ by $10 \mathrm{~km}$. The expected endurance is 4 hours at the flight speeds as low as $37 \mathrm{~km} / \mathrm{hr}$ (20 knots), following the terrain at altitudes down to $10 \mathrm{~m}$ above ground level and carrying payload of $10 \mathrm{~kg}$. The projected size of this "GeoSurv II" will allow design, construction and testing of the full-scale vehicle by the M\&AE teams over a four-year period. 


\section{Distinctive features}

Several UAV design teams have already experienced the complex problems that can occur when attempting to integrate an avionics system in a flying vehicle. We envisage a step increase in complexity as the team starts a technology development phase for the GeoSurv II system in September 2004. For the last two years, the ATB flight test programs have been rigorously planned and executed under the SFOC rules giving the students an introduction to aircraft certification.

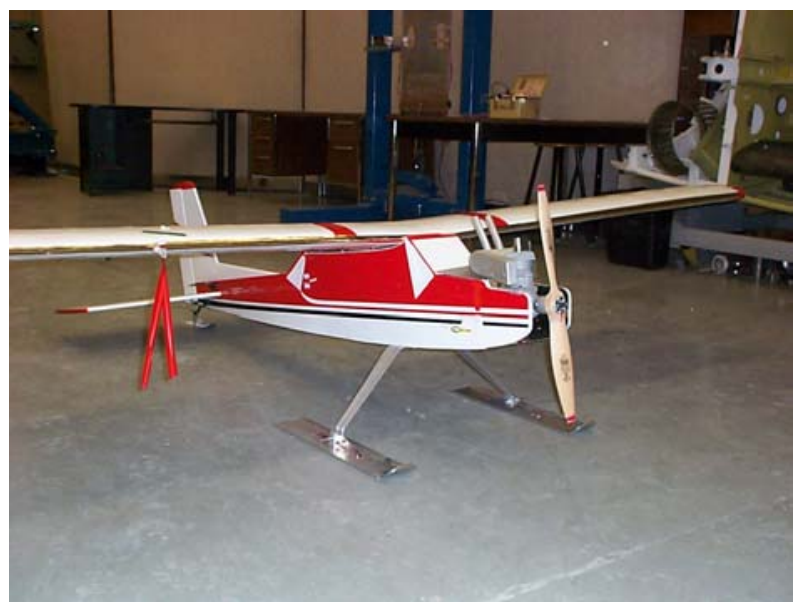

Figure 13. Avionics test bed

\section{Conclusions}

Experience with large team projects in M\&AE at Carleton has led to several conclusions:

- Students look forward to and value the design project experience;

- Feedback from industry strongly supports this format of project; and

- Faculty, though fully aware of the resourceintensive nature of the projects, are fully committed to the continuing evolution of this project style.

One of the aerospace industry supporters has expressed his view of the team project approach as follows:

"...the Carleton program mirrors the systems and procedures used in high technology companies ... to ensure that advanced products can be delivered with tremendous improvements in time to market while increasing reliability at entry-into-service, and maintaining stringent budget limits...The Carleton Faculty has developed their program to give new engineers the tools they need to integrate quickly into the industrial environment and reduce training once in place...”.

Our ultimate aim is to receive the same type of industry feedback ten and twenty years from now. 